\title{
Podcasts in the teaching media space
}

\author{
Gyulnara Basenko*, and Victoria Baskakova \\ Don State Technical University, 344002, Rostov-on-Don, Russia
}

\begin{abstract}
This article focuses on the podcasts in the learning media space. Modern educational technologies and the Internet resources have significantly expanded the possibilities of organizing the process of learning a foreign language. Podcasts as an innovative learning tool are an effective way of building socio-cultural and communicative skills. Podcasts are audio or video materials prepared by native speakers that are freely available on the Internet, available for download and reuse. The main difference between podcasts and television or radio is the ability to use them regardless of the specific time and place. The advantages of podcasts include their availability, variability, free choice, periodic updates, relevance, mobility.

The teaching media space offers, along with specialized educational podcasts, information, music, comedy podcasts, audiobooks, news in politics and sports, game channels. The main features of educational podcasts are: authenticity, relevance, multi functionality, multi-channel perception, mobility of the used technical means, productivity. Based on the analysis of various foreign language educational podcasts, 5 types were identified, classified by the content. Such podcasts can be recommended and successfully used not only in class, but also at home.

Using the theme "Food" as an example, the audio podcast RealLife English Podcast \# 180: In the Kitchen (Cooking Expressions) aims to develop students' auditory skills as well as communication skills using theme vocabulary in speech.

Thus, podcast technology has great potential for further development, especially in the context of the actualization of distance learning.
\end{abstract}

\section{Introduction}

Modern society is developing rapidly and issues new challenges for education [1]. Its close interaction with the digital space in all spheres of life including education has become one of the priority areas in society [2]. The use of new educational technologies and the Internet resources has expanded the possibilities of organizing the process of teaching foreign languages [3]. The content of the Internet makes it possible to receive up-to-date and authentic information on a topic of interest, as well as being translated in the foreign language. By accessing a foreign language Internet resource, the student is immersed in a genuine language environment that forms socio-cultural and communicative skills $[4,5,6]$.

* Corresponding author: julia.bass@mail.ru 
The use of this potential significantly expands the boundaries, accessibility and the level of teaching a foreign language. Podcasts are such an innovative resource in the teaching media space.

Along with other Internet resources, podcasts are an integral educational tool that allows you to solve complex problems within the framework of the formation of a student's foreign language competence [7]. Their usage demonstrates the mobility of the modern education system as a whole, its adaptive nature, as a timely adaptation to the changing needs and requirements of the society.

Podcasts, as an innovative means of teaching foreign languages, are audio or video materials prepared by native speakers that are freely available on the Internet and are available for download and reuse. The advantages of podcasts include their availability, variability, free choice, periodic updates, relevance, mobility. The ability to download podcasts to any device for free with their subsequent use makes them universal and multifunctional. This innovative tool allows in the educational process to address such types of speech activities as listening, speaking, writing and develop various kinds of skills: listening to foreign language speech, working with the new vocabulary, predicting information, forming inferences and performing tasks based on what was heard.

\section{Materials and methods}

The research presented in this article is part of a broader study on the effectiveness of audio podcasts. The study was conducted in the format of a written survey, which included a section on questions of students were asked to point out the effectiveness or ineffectiveness of audio podcasts.

The section contained both open-ended questions, to which respondents could answer in a free form, and questions with a list of answers, from which respondents were asked to choose one or several options. At the same time, there was always an opportunity to supplement the answer if, in the opinion of the respondent, the proposed options were not complete, accurate or comprehensive.

\section{Results}

The word "podcast" gets its name from two English words: iPod (a miniature device for listening to audio files in mp3 format) and broadcast. Thus, the term "podcasting" has acquired the following meaning: a kind of informational audio or video broadcasting on the Internet. Today, podcasts have become an integral part of the educational space, especially when learning a foreign language in a distance form. Podcasts are used as a means of listening to information or viewing it in a foreign language based on the language and thematic content corresponding to the curriculum in order to develop listening skills and skills in working with the information received [8]. The main difference between podcasts and television or radio is the ability to use them regardless of a specific time and place, which determines their convenience and accessibility [9].

In the educational process, podcasts can be lectures, audiobooks, broadcasts, conversations, or other additional material that promotes the educational goals of the teacher and students. The media space offers, along with specialized educational podcasts, also information, music, comedy podcasts, audiobooks, news in the field of politics and sports, game channels [10]. Audio and video blogs are of particular interest to students. Any type of podcast can be used for educational purposes at different levels of language proficiency.

The following features of educational podcasts are: 
1. Authenticity. The introduction of authentic materials into the learning process involves the assimilation of authentic vocabulary, phraseological units, grammatical constructions, verbal and non-verbal communication codes, and the cultural features of a native speaker by students. The main task of authentic podcasts is still students's getting communicative and cognitive skills, which they would perform in similar situations in real life [11]. For example, we usually listen to the news to get acquainted with the events taking place in the world and to find out the details of a particular phenomenon or incident. In the curriculum, this type of podcast as a news program should be used to get a general understanding of information and specific details [12]. However, the possibility of using podcasts specially created by methodologists, with an orientation to the target language, is not excluded. The use of materials of different levels of complexity is justified taking into account the level of the student's language proficiency, his interests and needs.

2. Relevance. The podcasting system includes a selection of diverse topics: sports, fashion, nutrition, medicine, education, global problems of humanity and much more. This allows you to use podcasts in foreign language classes if you want a more detailed consideration of a particular educational topic. Continuous updates of original news podcasts, for example, in online versions of newspapers and magazines or TV shows, ensure the relevance of the audio and video material used for educational purposes. This makes it possible for students to give more strong and relevant arguments when characterizing the modern socio-cultural component of the country of the target language, to promote understanding of the internal processes of the language, as well as to give an idea of a lively spoken language that is in dynamics.

3. Multifunctionality. The peculiarity of podcasts is in their universal application in the development of all types of speech activity: reading, speaking, writing, listening. In addition, podcasts contribute to the assimilation of the socio-cultural competence of students: one way or another, they immerse themselves in the culture of the language being studied, get acquainted with national traditions, customs, holidays, the education system, and so on. This makes it possible to fully and consciously cognize the culture of other peoples, to understand the problems of a global scale better [13].

4. Multi-channel perception. When choosing podcasts, preference is given to materials that provide the perception of both visual (video, photo or text) and auditory (audio) information. This allows to use various organs of perception simultaneously in the classroom, which, of course, helps to expand the receptive capabilities of students [14]. Perceived information will be understood more easily and more meaningfully if it is supported by certain objects and actions.

5. Mobility of the used technical means. Podcasts can be listened to on any device adapted for this: phone, computer, laptop, tablet, player. This wide range of devices allows you to access podcast content anytime and outside the educational institution. The use of podcasts on personal purposes leads to an expansion of the learning environment, as the students can improve their knowledge in their free time, based on their personal receptive skills. It should also be noted the ability to adjust the speed of the selected podcast, turn on / off subtitles, return to the material already listened to.

6. Productivity. As a result of using podcasts, not only the expected educational result can occur, but also the manifestation of students' initiative to create their own podcast. From the point of view of productivity, podcasting is a strong impulse for learning a foreign language in terms of the activity approach [15]. By creating and publishing audio or video materials on the network, students work with promising information technology in a real situation.

Consequently, podcasts are multifunctional and provide a number of unique opportunities for organizing the process of teaching a foreign language in general and can be used both within an educational institution and for organizing independent work [16]. 
Based on the didactic characteristics of podcasts, we can talk about the flexibility of this innovative means of teaching a foreign language, which is especially important and relevant in a constantly changing and developing world.

Let us consider the educational podcasts aimed at learning English. Based on the analysis of various foreign language educational podcasts, the following types were identified, classified by the content:

1. Podcasts as complete English lesson. Breaking News English is a site where teachers can find audio files with tasks already developed for them. This podcast can be taken as the basis for a full-fledged lesson, and in addition, used as a ready-made material for independent work at the stage of knowledge control. Nevertheless, this particular podcast specializes in the older age group of students, since the tasks are quite voluminous, require independent work skills, concentration and perseverance.

2. Podcasts for working with vocabulary material. Learn English with TV Series is an educational YouTube channel based on popular movies and TV series, such as the beloved Harry Potter saga or the Friends series, and vocabulary is detailed in 15-30 minute videos. Words are considered not only in the context of the video, but also in their basic meaning. This type of podcast is ideal for organizing the material for additional English lessons: circles, extracurricular activities of students. "English in Songs" is a type of audio podcast that can be offered to students as the material for further study. The episodes last no more than 15 minutes, and in this short time you can learn not only what the performers are singing about, but also learn words and expressions that will help in communication.

3. Podcasts that develop phonetic. LENGVIST is a video podcast aimed at practicing the articulation of English sounds, putting the stress. The advantage of this channel is a wide range of tasks that meet various learning objectives: analysis of individual sounds: monophthongs, diphthongs, triphthongs, articulatory gymnastics.

4. Podcasts as stories. Voice of America Learning English — is the Audio podcast with news and short stories. It is worth noting that the speaker's tempo is average, which allows the student to accept the maximum amount of material.

5. Podcasts as jokes. Luke's ENGLISH Podcast — is a podcast of an English teacher. The jokes integrated into his podcast make language learning more interesting and stimulate students' attentive listening.

It is often assumed that podcasts are tools for the development of exclusively listening and speaking skills, but in fact they go beyond only two types of skills and cover other skills [17]. Some podcasts contain additional text material. This assumes the presence of a script, subtitles, or developed worksheets with vocabulary and lexical and grammatical exercises, which allows foreign users to receive the information they need without any restrictions. In the absence of a complete understanding of the podcast information by ear, the student has the opportunity to turn to the textual material and fill in the gaps, which makes work on vocabulary productive and allows them to study independently. Such podcasts can be recommended and successfully used by students not only in the classroom, but also at home.

Separately, attention should be paid to a special type of the educational podcast, carried out by the students themselves within the framework of a certain topic during the educational process. The creation of their own audio and video materials can be used at the final stage of mastering a certain topic, refers to the active activity of the students, requiring them to have certain skills and abilities. An educational podcast of this type has its own difficulties and peculiarities. Its implementation requires not only the desire and interest from the students' part, but also the involvement and assistance of the teacher, as well as the technical skills for creating audio and video materials.

According to A.G. Solomatina, an educational podcast is understood as an audio or video created by students in a foreign language in accordance with the language and 
thematic content of the curriculum and posted on the podcast server for further use in the educational process [18]. Based on the definition, we can identify the formal requirements that must be met in order for a podcast to be called educational:

- the language of the recording must be studied by the student as a foreign one;

- the duration of the sound should not exceed 4 minutes;

- the topic should correspond to the content of the curriculum;

- recording types: monologue, dialogue, group recording;

- recording format: audio or video [19].

One of the main components of the educational process is the organization of students' extracurricular activities. Such activity is understood as purposeful, educational work, coordinated by a teacher, carried out after school hours as a part of the curriculum [20]. In other words, this is one of the forms of organizing students' free time, contributing to the creation of conditions necessary for the development of their personality, the formation of cognitive activity, morality and the course of socialization process [21]. The objectives of this work are to generate and further deepen students' interest in various knowledge and types of activities, to discover and develop their talents and abilities, and the cultural organization of their leisure time. Podcasts, while claiming the versatility of their use as a means of teaching a foreign language, are designed to fulfill these tasks. So, in extracurricular classes for teaching English, podcasts can be presented in the form of entertaining, but at the same time as cognitive and informative materials. Almost all people love to watch films, TV series and cartoons, so the teacher can conduct a survey of the film industry works and based on its result, select the appropriate podcast.

Podcasts are unique in the fact that, due to their diversity, they can be integrated into any foreign language learning activity. The study of such educational topics as family, hobbies, food, education, sports, travel and many others can be carried out using audio and video materials, which will not only diversify the process of acquiring knowledge and the way the teacher presents information, but also provide an opportunity to choose the difficulty of the material in depending on the students' level of knowledge.

For example, the favorite topic "Food", which can be interpreted as "We are what we eat", "Food in our life", is detailed in the RealLife English Podcast \# 180: In the Kitchen (Cooking Expressions) audio podcast. This issue is useful for learners with an advanced level of English proficiency. First of all, it is effective for replenishing their vocabulary on the topic "Food".

While listening to this podcast, the following expressions and proverbs are considered:

- enchiladas: traditional Mexican food

- a signature dish: a recipe that identifies an individual chef or restaurant

- leftovers: food remaining after the rest has been eaten

- to be blown away: to be impressed or excited by something

- something isn't as easy as pie: something is very difficult

- a piece of cake: something that is very easy to do

- minced beef: beef that has been finely chopped with a knife or a meat grinder.

- someone is the apple of your eye: someone that you really care about

- the apple doesn't fall far from the tree: phrase that is typically said in connection

- with children who show qualities that are similar to those of their parents

- you can't have your cake and eat it too: you can't have everything you want

- the proof is in the pudding: you can only judge the quality of something after you

- ave tried, used, or experienced it

- someone has a bun in the oven: someone is pregnant

- that's the way that cookie crumbles: another way of saying "that's the way it is"

- go nuts: go crazy 
- to be paid peanuts: to pay someone a very small amount

- to be littered with something: to be full of something

- two peas in a pod: when you have two things that are very similar

- to buy a lemon: when you get something new (like a car, computer, etc.) and it has a lot of problems

- if life gives you lemons, make lemonade: bring something positive from a negative thing, etc. [22].

The plan for working with this material includes the first listening so that the students determine the main idea of the podcast, then brainstorm in the vocabulary related to this topic. After that, the students are given a list of new phrases, the recording is listened to again and they try to understand the meaning of these expressions.

Sample tasks for consolidating new material can be:

1. writing your own sentences using the learnt phrases;

2. acting out a dialogue with the use of the appropriate vocabulary;

3. discussion about the information heard.

As we can see, the main goal of this audio material is the development of students' auditory skills and the presentation of theme words, phrases, proverbs and phraseological units.

To determine the effectiveness of using audio podcasts in teaching a survey of the firstand the fourth-year students of Don State Technical University was conducted. The students were to express their attitude towards the audio podcasts in the educational process.

The students were asked to point out the effectiveness or ineffectiveness of audio podcasts on the following issues:

1) Teachers use audio podcasts at the lesson;

2) Teachers set tasks with audio podcasts as homework;

3) Teachers recommend students to work with audio podcasts on their own.

The students of both years had the possibility to use the third column in case of difficulty in answering. Then the results were analyzed and presented in the table 1 as a percentage.

Table 1. Table the effectiveness or ineffectiveness of audio podcasts

\begin{tabular}{|c|c|c|c|c|c|c|}
\hline $\begin{array}{c}\text { The effectiveness or } \\
\text { ineffectiveness of audio } \\
\text { podcasts }\end{array}$ & \multicolumn{2}{|c|}{$\begin{array}{c}\text { Considered } \\
\text { effective } \\
\%\end{array}$} & \multicolumn{2}{|c|}{$\begin{array}{c}\text { Considered } \\
\text { ineffective } \\
\%\end{array}$} & \multicolumn{2}{|c|}{$\begin{array}{c}\text { Find it difficult } \\
\text { to answer } \\
\%\end{array}$} \\
\cline { 2 - 7 } & 1 year & 4 year & 1 year & 4 year & 1 year & 4 year \\
\hline $\begin{array}{c}\text { 1) Teachers use audio } \\
\text { podcasts at the lesson; }\end{array}$ & 58.4 & 87.6 & 25 & 8 & 16.6 & 4.4 \\
\hline $\begin{array}{c}\text { 2) Teachers set tasks } \\
\text { with audio podcasts as } \\
\text { homework; }\end{array}$ & 75.4 & 87.6 & 8 & 8 & 16.6 & 4.4 \\
\hline $\begin{array}{c}\text { 3)Teachers recommend } \\
\text { students to work with } \\
\text { audio podcasts on their } \\
\text { own. }\end{array}$ & 50 & 80.6 & 33.4 & 15 & 16.6 & 4.4 \\
\hline
\end{tabular}




\section{Discussion}

Based on the above research results, we can consider the hypothesis that that the first-year students are less informed about the use of audio podcasts in the educational process as well as about their effectiveness in learning a foreign language.

These research confirm that audio podcasts have become a relevant and accessible tool for learning a foreign language. The majority of the first-year students $(75.4 \%)$ and the fourth-year students $(87.6 \%)$ almost equally found it effective to use audio podcasts as homework. The first-year students underestimated the effectiveness of independent work with foreign-language audio podcasts $(33.4 \%)$ more than the fourth-year students $(15 \%)$. On the contrary, the fourth-year students preferred working with audio podcasts, and also realized its effectiveness, both in the classroom and as homework (the same indicators 87.6). Moreover, in working with audio podcasts under the guidance of a teacher, the fourth-year students saw the effectiveness more $(87 \%)$ than the first-year students did $(50 \%)$. The first-year students did not yet realize the effectiveness of working with audio podcasts either in the classroom (25\%) or on their own (33.4).

\section{Conclusions}

The results of the study confirm the hypothesis put forward that podcast technology has a lot of potential for further development, despite the fact that it is relatively new. Already now the group of supporters of this method is growing: on the one hand, podcasts affect the interests of young people, broadcasting interviews with famous people, speaking at TED TALKS, BBC Radio conferences, on the other hand, universities are actively integrating them into the educational process, especially in the context of the actualization of distance learning. All types of podcasts as an innovative means of teaching a foreign language can be effectively used both in the classroom work and in the independent work of students using modern digital technologies.

\section{References}

1. E.V. Murugova, T. B. Mikheeva, E3S Web of Conferences 210, 18095 (2020). doi: https://doi.org/10.1051/e3sconf/202021018095.

2. S.V. Pervukhina, G.I. Radchenko, E3S Web of Conferences 210, 18036 1-10 (2020). https://doi.org/10.1051/e3sconf/202021018036.

3. M. Asrorova, Young scientist 6, 564-566 (2015).

4. E. Egorova, N. Bulankina, O. Mishutina, V. Tsybaneva, Features of pedagogical design of a digital language course for the university students, INTED2021 Proceedings. doi: 10.21125/inted.2021.0159 (2021).

5. E. Egorova, N. Bulankina, O. Mishutina, V. Tsybaneva, Technology for designing a digital educational course for the university students, INTED2021 Proceedings. doi: 10.21125/inted.2021.0165, (2021).

6. T. Lopatukhina, E. Egorova, V. Sizyakina, Pedagogical management in the virtual information and educational environment of the university, ICERI 2020 Proceedings. doi: 10.21125/iceri.2020.0640 (2020).

7. A. Popova, Scopus, Procedia, Social and Behavioral Sciences 2 (2), 5034-5038 (2012).

8. P. Sysoev, Language and culture 4 (20), 115-127 (2012).

9. A. Musina, Pedagogy. Questions of theory and practice 6, 564-566 (2019). 
10. V. Khaikin, Activity (characteristics and development) (MODEK, Voronezh, 2000).

11. P. Sysoev, Foreign languages at school 1, 8-15 (2008).

12. P. Sysoev, Language and culture 2 (26), 189-201 (2014).

13. G. Dmitriev, Multicultural education (Public education, Moscow, 1999).

14. A. Volodin, Bulletin of the Tula State University 1, 378-384 (2013).

15. S. Titova, Information and communication technologies in humanitarian education: theory and practice. Textbook (P-Center, Moscow, 2009).

16. V. Veselova, Formation of listening skills through the use of podcasts in the educational process (Science of SUSU,1029-1035 (2015).

17. A. Sukhanova, Podcasts in teaching listening, Problems and prospects for the development of education: materials of the VIII Intern. Scientific. conf. (Krasnodar, February 2016), Krasnodar: Novatsiya, 73-75 (2016).

18. A. Solomatina, Foreign languages at school 9 (26), 71-74 (2012).

19. P. Sysoev, M. Evstigneev, Foreign languages at school 6, 8-11 (2009).

20. L. Yakushina, Foreign languages at school 5, 89-90 (1975).

21. O. Lingevich, Scientific Almanac 12, 292-294 (2015).

22. RealLife English Podcast \#180: In the Kitchen (Cooking Expressions) Homepage, :https://reallifeglobal.com/in-the-kitchen/, last accessed 2021.20.01. 